Article

\title{
Adsorptive Removal of Carbamazepine and Diatrizoate in Iron Oxide Nanoparticles Amended Sand Column Mimicing Managed Aquifer Recharge
}

\author{
Soon Uk Yoon ${ }^{1}$, Biswanath Mahanty ${ }^{2}$ and Chang Gyun Kim ${ }^{1, *}$ \\ 1 Department of Environment Engineering, INHA University, Incheon 22212, Korea; suyoon@inha.edu \\ 2 Department of Biotechnology, Karunya University, Coimbatore 641114, India; bmahanty@gmail.com \\ * Correspondence: cgk@inha.ac.kr; Tel.: +82-328607500; Fax: +82-328762351
}

Academic Editors: Niels Hartog and Pieter J. Stuyfzand

Received: 6 February 2017; Accepted: 30 March 2017; Published: 2 April 2017

\begin{abstract}
The sorption-desorption of recalcitrant pharmaceuticals in sand/soil columns can be used to infer performance of managed aquifer recharge. Removal of carbamazepine (CBZ) and diatrizoate (DTZ) from synthetic wastewater, containing $100 \mu \mathrm{g} \cdot \mathrm{L}^{-1}$ of each pharmaceuticals, was studied in recirculating sand columns amended with uncoated or methacrylic acid (MAA) coated magnetite nanoparticles. Removal of CBZ and DTZ in MAA-magnetite column $(68.34 \%$ and $61.91 \%$, respectively) was much higher than that with uncoated magnetite $(53.47 \%$ and $50.26 \%$, respectively). Rapid decrease of dissolved organic carbon concentrations across nanoparticle amended columns (between $42.28 \%$ and $50.08 \%$ on Day 1), followed by slow recuperation suggests adsorption-desorption dynamics and competition of dissolved organic matter for sorption sites. Core-level binding energy and charge analysis for $\mathrm{Fe}(2 \mathrm{~s})$ and $\mathrm{O}(1 \mathrm{~s})$ in X-ray photoelectron spectroscopy suggests involvement of physisorption process on the NP surfaces.
\end{abstract}

Keywords: MAR; column test; pharmaceutical pollutants; methacrylic acid; magnetite

\section{Introduction}

Increasing use or abuse of different pharmaceuticals substances compounded by their persistence and non-biodegradability has resulted in their omnipresence in different environmental compartments. The pharmaceuticals and personal care products (PPCPs) often found near livestock manure and landfill, can be released during rainfall as a non-point source [1]. Even at trace levels, PPCPs are toxic to human, animals and ecosystem. Results from studies pertaining to PPCPs removal in conventional sewage treatment plants are often not promising, unpredictable and variable, which necessitate alternative treatment strategy.

Managed aquifer recharge (MAR) is one of the viable water resource management strategies that aim to replenish aquifer with rainwater or treated effluent from sewage treatment plants [2]. Though a well-known technology, attention on MAR has only been increased in recent times for fulfilling storage-treatment-distribution as well as "naturalizing" water from a public perception perspective [3]. Pilot-scale test of MAR on improving basic water quality parameters (e.g., suspended solids, biochemical oxygen demand, dissolved organic carbon, and chemical oxygen demand), microbiological analysis (e.g., total bacteria count, Faecal coliforms, and E. coli), and trace elemental or salinity related assessment has been demonstrated [4]. Soil aquifer treatment (SAT), a variant of MAR, is adopted to treat sewage effluent where reclaimed water is intermittently infiltrated through unsaturated zone "infiltration ponds" to facilitate nutrient and pathogen removal before reaching the aquifer [5]. Accompanying organic contaminants can either be biodegraded by environmentally relevant microbial community in SAT or be retained in soil through physical and chemical adsorption [6]. 
Adsorption is an important mechanism for PPCPs removal during soil passage. The efficiency depends on the organic carbon partition coefficient or acid dissociation constant of organic micropollutants. The latter may be more relevant for the fate of acidic PPCPs [7]. Iron oxide nanoparticles are being explored for fast adsorption and subsequent separation of organic contaminants from large volume water samples in ex-situ process [8]. To have better and tunable contaminant adsorption, surface of iron oxide nanoparticles are often functionalized by organic or inorganic materials appropriate for ease of dispersion and surface exchange reactions with organic contaminants [9]. The adsorption continues until surface functional sites are fully occupied, and thereafter contaminants diffuse into adsorbent for further interactions [8]. In this study, use of the carboxyl functionalized (methacrylic acid coated) nanoparticle into sand-column infiltration system was evaluated replicating the managed aquifer treatment system. Removal of carbamazepine (CBZ) and diatrizoate (DTZ) in acrylic sand column was monitored for 18 days and the results have been discussed.

\section{Materials and Methods}

\subsection{Artificial Wastewater}

In order to simulate the effluent of sewage treatment plant, $200 \mu \mathrm{g}$ each of CBZ (5H-Dibenz[b,f]azepine-5-carboxzmide, $\mathrm{C}_{15} \mathrm{H}_{12} \mathrm{~N}_{2} \mathrm{O}$ ) and DTZ (3,5-Diacetamido-2,4,6-triiodobenzoic acid sodium salt, $\mathrm{C}_{11} \mathrm{H}_{8} \mathrm{I}_{3} \mathrm{~N}_{2} \mathrm{NaO}_{4} \cdot \mathrm{xH}_{2} \mathrm{O}$ ) was dissolved in $2 \mathrm{~L}$ of distilled water ( $\mathrm{pH}$ 6.8-7.2).

\subsection{Synthesis of Magnetite and MAA Coated Magnetite}

The iron oxide NPs were synthesized by the co-precipitation of ferrous and ferric ions in alkaline solution and were subsequently coated using MAA. The detailed methodology has been described in our earlier publication [10]. Briefly, an aqueous solution consisted of $10 \mathrm{~g} \cdot \mathrm{L}^{-1}$ of $\mathrm{FeCl}_{2} \cdot 4 \mathrm{H}_{2} \mathrm{O}$ and $16.25 \mathrm{~g} \cdot \mathrm{L}^{-1}$ of $\mathrm{FeCl}_{3} \cdot 6 \mathrm{H}_{2} \mathrm{O}$ was added dropwise into $20 \mathrm{M}$ of $\mathrm{NaOH}$ solution under mechanical stirring. Once the suspension turns black, magnetite NPs was recovered and washed twice with distilled water. To functionalize the surface of magnetite, $5.75 \mathrm{~g} \cdot \mathrm{L}^{-1}$ of sodium dodecyl sulfate (SDS) solution was added to the black suspension and then heated to $70{ }^{\circ} \mathrm{C}$, adjusted to $\mathrm{pH}$. For polymerization reaction, the $\mathrm{K}_{2} \mathrm{~S}_{2} \mathrm{O}_{8}$ initiator was added.

The synthesized MAA-magnetite had a size less than $10 \mathrm{~nm}$ and had a core-shell structure as revealed in transmission electron microscopy (TEM). The specific surface area of magnetite and MAA-coated magnetite, as measured in nitrogen adsorption-desorption BET method, were 113.29 and $117.66 \mathrm{~m}^{2} \cdot \mathrm{g}^{-1}$, respectively. Further characterization of MAA-magnetite using scanning electron microscopy (SEM) and Fourier transform infrared spectroscopy (FTIR) can be found elsewhere [10,11].

\subsection{Column Experiment}

Three acryl SAT columns (i.d.: $5 \mathrm{~cm}$, height: $65 \mathrm{~cm}$ ) was packed with pre-autoclaved standard sand (density $1.46 \mathrm{~g} \cdot \mathrm{L}^{-1}$, diameter $0.2-1.2 \mathrm{~mm}$, porosity 0.40 ) from the bottom to $55.5 \mathrm{~cm}$ height of the column (Figure 1). One gram of magnetite or MAA-magnetite was layered on top of sand packing in two columns. The third column, without nanoparticles, served as control. Synthetic wastewater (2 L) spiked with CBZ and DTZ each at a concentration of $100 \mu \mathrm{g} \cdot \mathrm{L}^{-1}$ was slowly recirculated through the column with a peristaltic pump (Watson-Marlow 520S/R, Cornwall, UK) for 18 days using. Flow rate was set at $0.5 \mathrm{~mL} \cdot \mathrm{min}^{-1}$ with a calculated retention time of $12.1 \mathrm{~h}$. About $20 \mathrm{~mL}$ column effluent was sampled for analysis. Following concentration assessment, equivalent volume and concentration of CBZ and DTZ was replenished into synthetic wastewater circulation on the same day. Control sand-column test was included in the design under identical condition without magnetite or MAA-magnetite amendment. 


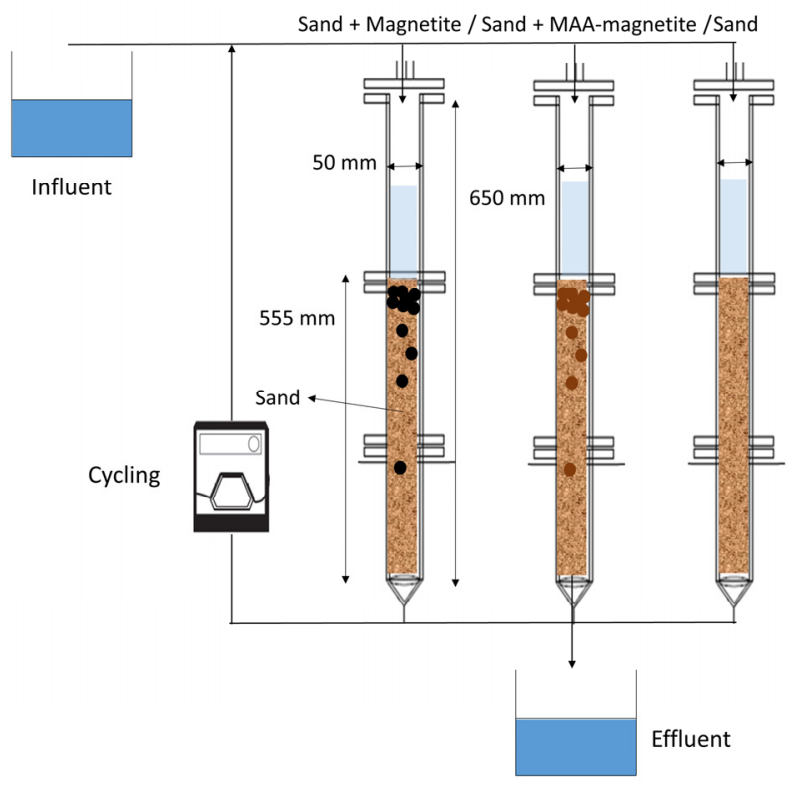

Figure 1. Schematic diagram of the operating sand column adopted for carbamazepine (CBZ) and diatrizoate (DTZ) adsorption.

\subsection{Sample Pre-Processing and Analysis}

\subsubsection{Sample Pretreatment for CBZ and DTZ Analysis}

The aqueous phase CBZ and DTZ in effluent of column tests were preprocessed through solid phase extraction (SPE). Samples were adjusted to $\mathrm{pH} 2.7$ by $3.5 \mathrm{M} \mathrm{H}_{2} \mathrm{SO}_{4}$ and then filtered through $0.45 \mu \mathrm{m}$ glass fiber membrane. Clarified filtrates were extracted in HLB (Oasis ${ }^{\mathrm{TM}}, 60 \mathrm{mg}$, $3 \mathrm{~mL}$, Milford, MA, USA) and ENV+ (Waters ${ }^{\circledR}, 50 \mathrm{mg}, 3 \mathrm{~mL}$, Charlotte, NC, USA) SPE cartridge. The cartridges pre-conditioned with $3 \mathrm{~mL}$ methanol and $3 \mathrm{~mL}$ deionized water were installed on a vacuum manifold. Samples was loaded into the cartridges at a rate of $15 \mathrm{~mL} \cdot \mathrm{min}^{-1}$, washed two times with $3 \mathrm{~mL}$ deionized water, and subsequently dried under vacuum for $10 \mathrm{~min}$. Finally, CBZ and DTZ were eluted with $8 \mathrm{~mL}$ of methanol, fractions were pooled and concentrated (about $1 \mathrm{~mL}$ ) in nitrogen gas aided evaporation system (TurboVap II, Biotage, Uppsala, Sweden).

\subsubsection{HPLC Analysis of CBZ and DTZ}

HPLC analysis conditions for CBZ and DTZ have been detailed in a previous work [10]. The concentrated samples were loaded into a Zorbax Eclipse XDB-C18 column $(4.8 \mathrm{~mm} \times 150 \mathrm{~mm}$, $5 \mu \mathrm{m}$, Agilent technology, Santa Clara, CA, USA). A binary gradient consisting of $0.1 \% \mathrm{v} / \mathrm{v}$ formic acid solution and methanol at a flow rate of $1 \mathrm{~mL} \cdot \mathrm{min}^{-1}$ were utilized under UV-detection at $258 \mathrm{~nm}$. The mobile phase gradient was as follows: $5 \%$ methanol held for $3.5 \mathrm{~min}$, increased linearly to $50 \%$ for $5 \mathrm{~min}$ and held for $2 \mathrm{~min}$, which then increased linearly to $60 \%$ and $80 \%$ every 2 min and held for $2 \mathrm{~min}$, respectively, stepped to $100 \%$ for $16 \mathrm{~min}$. Column was washed with $100 \%$ methanol to remove any residue in between sample runs.

\subsubsection{DOC Analysis}

Dissolved organic carbon content in circulating synthetic wastewater, after filtration through the $0.45 \mu \mathrm{m}$ glass fiber filter, was measured using a TOC analyzer (Sievers TOC 900, GE Analytical Instruments, Boulder, CO, USA). 


\subsubsection{Metals Analysis}

To monitor possible leaching of nanoparticle or other minerals (i.e., $\mathrm{Fe}, \mathrm{Mn}$ and $\mathrm{Cu}$ ) in effluent, metal concentration was measured in by ICP-OES (Liberty RL, Varian, Walnut Creek, CA, USA). Samples $\left(30 \mathrm{~mL}\right.$ ) were filtered through $0.45 \mu \mathrm{m}$ membrane filter, acidified with $1 \mathrm{~mL}$ of $\mathrm{HNO}_{3}$ (to dissolve any accompanying magnetite) prior to analysis.

\subsubsection{XPS Analysis}

The chemical and physical surface properties of magnetite, before and after column test, were comparatively assessed in XPS (K-Alpha, Thermo scientific, Darmstadt, Germany). A mixture of magnetite and sand was sampled from column at the end of experiment, and magnetite was separated from sand using magnet. Oven-dried samples were mounted on a standard sample holder and analyzed using the micro focused, monochromated $\mathrm{Al} \mathrm{K \alpha}$, X-ray source with a spot size of $400 \mu \mathrm{m}$. The Fe and $\mathrm{O}$ present on the samples were identified from the survey spectra. The survey scans started at $1400 \mathrm{eV}$ and ended at $0 \mathrm{eV}$, with a step size of $1 \mathrm{eV}$ and dwell time of $200 \mathrm{~ms}$ [11].

\section{Results and Discussion}

\subsection{CBZ and DTZ Removal}

The removal of CBZ and DTZ in the sand columns are shown in Figure 2a,b. In control sand-column without nanoparticles, initial CBZ and DTZ concentrations (both $100 \mu \mathrm{g} \cdot \mathrm{L}^{-1}$ ) dropped to 80.07 and $76.42 \mu \mathrm{g} \cdot \mathrm{L}^{-1}$, respectively, in 18 days. In magnetite added sand column, free CBZ and DTZ concentrations dropped to 45.80 and $53.04 \mu \mathrm{g} \cdot \mathrm{L}^{-1}$, respectively. Further improvement was evident with MAA coated magnetite where residual CBZ and DTZ concentrations were at 32.07 and $40.94 \mu \mathrm{g} \cdot \mathrm{L}^{-1}$, respectively.

Investigation on the fate of CBZ in wastewater treatment plant revealed that CBZ is not degraded or absorbed in activated sludge treatment or by subsequent purification treatments (i.e., polishing lagoons and gravel filters) [12]. However, reduction of CBZ in field studies been promising, where post SAT concentration was one order of lower than treated wastewater feed [13]. High affinity adsorption of CBZ and DTZ by MAA-magnetite nanoparticles in batch studies has been reported earlier with maximum adsorption capacities 77.30 and $112.46 \mathrm{mg} \cdot \mathrm{g}^{-1}$, respectively [10]. With a pKa value of 13.9, CBZ exists as a neutral compound and its adsorption onto sand (silica) in control or MAA-NP amended columns was not likely to be affected by $\mathrm{pH}$. The adsorption is attributable to a nonelectrostatic interaction involving hydrogen bonding, hydrophobic and Van der Waals interactions [14]. This hydrogen bonding is preferred when silica surface has a net positive charge at low $\mathrm{pH}$. However, at near neutral $\mathrm{pH}$ of synthetic wastewater employed in this study the adsorption of CBZ is somewhat less favorable on negative silica surface [15]. The MAA coated NPs exhibited somewhat better adsorption toward CBZ than in control column, possibly from a higher specific surface area, and larger pore volume of MAA functionalized NPs [16].

At near-neutral synthetic wastewater $\mathrm{pH}$, the molecules of DTZ are negatively charged $(\mathrm{pKa}=3.4)$. Three possible mechanisms for DTZ adsorption onto silica and the functionalized nanoparticles could be hypothesized, i.e., electrostatic interaction between the deprotonated DTZ molecules and the surface charges of the adsorbents, dipole-dipole interaction hydrogen bonding, and the hydrophobic interactions [17]. At $\mathrm{pH} 7$, silica surface as well as carboxyl group in MAA have a net negative surface charge, and so electrostatic interactions should decrease the adsorption of DTZ [18]. 
(a)

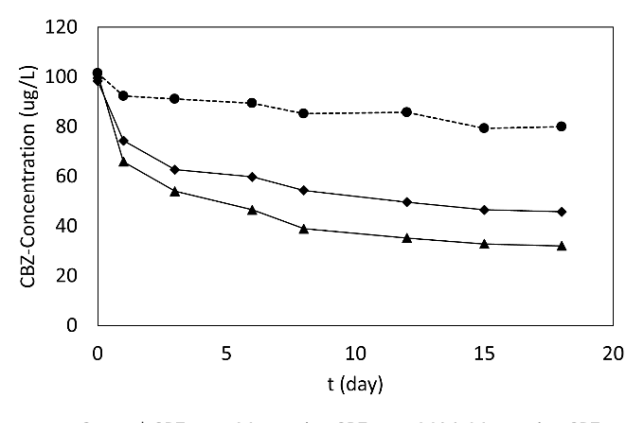

(c)

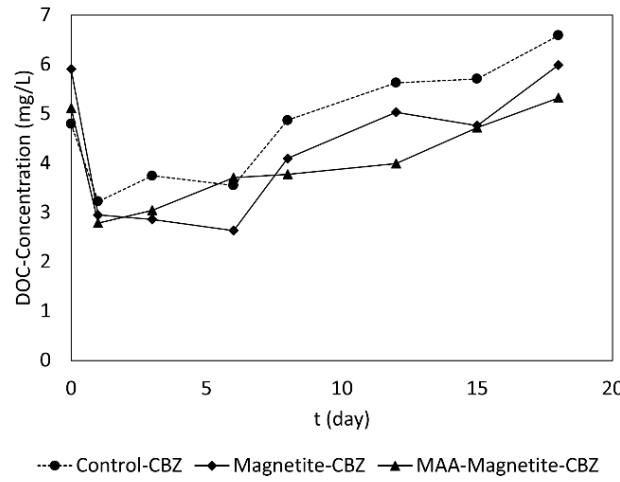

(b)

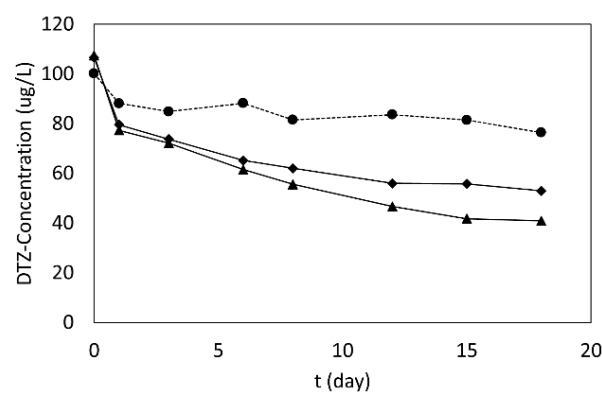

--Control-DTZ $\rightarrow-$ Magnetite-DTZ $\leftarrow$ MAA-Magnetite-DTZ

(d)

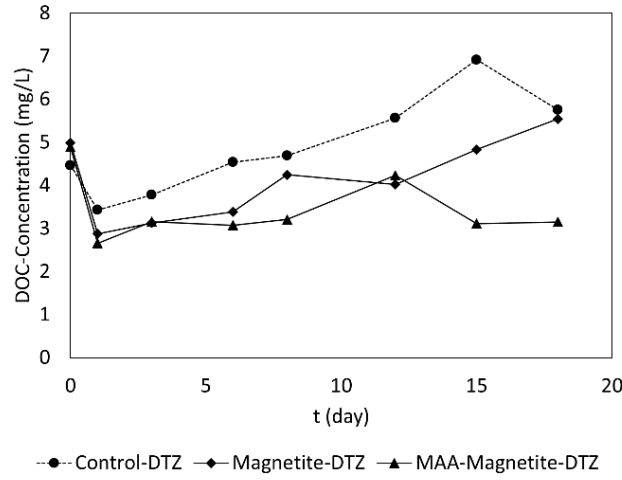

Figure 2. Residual concentrations of: (a) carbamazepine (CBZ); and (b) diatrizoate (DTZ) in control, magnetite and methacrylic acid (MAA)-magnetite amended sand-columns; and dissolved organic carbon (DOC) concentration profiles $(\mathbf{c}, \mathbf{d})$.

\subsection{DOC Trend in Sand Column Effluent}

The DOC variation during CBZ removal is shown in Figure 2c. In control columns without NPs, DOC concentration dropped from an initial value of 4.78 to $3.23 \mathrm{mg} \cdot \mathrm{L}^{-1}$ on the first experimental day, which subsequently increased from the third experimental day onward to $5.71 \mathrm{mg} \cdot \mathrm{L}^{-1}$ at the end of the experiment. Sets containing magnetite, DOC level declined from 5.91 to $2.64 \mathrm{mg} \cdot \mathrm{L}^{-1}$ for 6 days and then increased to $5.99 \mathrm{mg} \cdot \mathrm{L}^{-1}$. Similarly, in MAA-magnetite dosed sand column the DOC decreased from 5.12 to $2.79 \mathrm{mg} \cdot \mathrm{L}^{-1}$ in a day. DOC variations were also observed in column recirculating DTZ spiked water (Figure 2d). In control set, initial DOC concentration of $4.47 \mathrm{mg} \cdot \mathrm{L}^{-1}$ dropped down to $3.44 \mathrm{mg} \cdot \mathrm{L}^{-1}$ for a day. Likewise, DOC in magnetite dosed sand column decreased from 4.99 to $2.88 \mathrm{mg} \cdot \mathrm{L}^{-1}$. In presence of MAA-magnetite, though the DOC level decreased from 4.89 to $2.66 \mathrm{mg} \cdot \mathrm{L}^{-1}$ at initial experimental day, but remained nearly constant at $3.16 \mathrm{mg} \cdot \mathrm{L}^{-1}$ from the Day 3 to Day 18 . The DOC content of distilled water used to prepare the "simulated treated effluent" was only $230 \mathrm{ppb}$. Thus, the initial high DOC content in column effluent could be attributed to leaching of sand associated organic matters.

DOC concentration in the close loop recirculation system is dependents on equilibrium adsorption-desorption of either the sand matrix associated organic carbon and the pharmaceuticals included in the study. It should be noted that the "simulated treated effluent" adopted in this study is compositionally much simpler than expected in real situation, where the array of different organic or inorganic compounds is likely to influence adsorption of target contaminants. It is reasonable to presume that partition coefficient for carbamazepine is different from that of the dissolved organic matter (DOM) [19]. The DOC trend can result from a competition effect of the DOM on the solid-phase sorption sites or from complexation of carbamazepine with DOM which can reduce sorption of 
non-ionized organic compounds [20]. Neutral carbamazepine is likely to interact with the soluble organic matter and higher mobility of carbamazepine in soil profile been reported [19].

\subsection{Metal Leaching Behavior}

To assess of fate of iron oxide NPs in sand column, concentration of the inorganic ions, i.e., $\mathrm{Fe}, \mathrm{Mn}$ and $\mathrm{Cu}$, in the effluent was measured (Figure 3). Iron concentration in effluent decreased from 0.117 to $0.047 \mathrm{mg} \cdot \mathrm{L}^{-1}$ in control columns fed with CBZ. The higher initial concentration can be attributed to leaching from the sand particles, which was however re-adsorbed during the later experimental phase. The initial iron concentrations in sand column containing magnetite or MAA-magnetite was lower than the control column. The leached iron concentration fluctuated between 0.022 and $0.034 \mathrm{mg} \cdot \mathrm{L}^{-1}$ in sand columns fed with CBZ spiked water. Manganese concentration shoot-up to $0.028 \mathrm{mg} \cdot \mathrm{L}^{-1}$ for a day and copper concentration was maintained around $0.02 \mathrm{mg} \cdot \mathrm{L}^{-1}$ when DTZ spiked water was fed into magnetite or MAA-magnetite column.

(a)

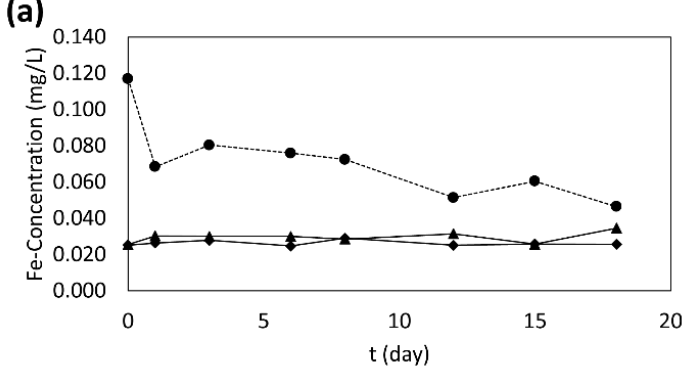

(c)

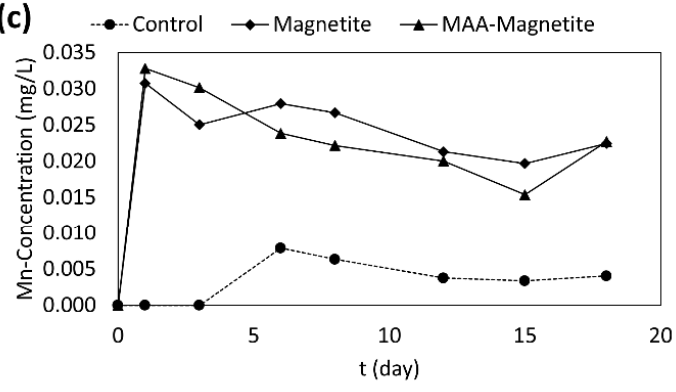

(e)

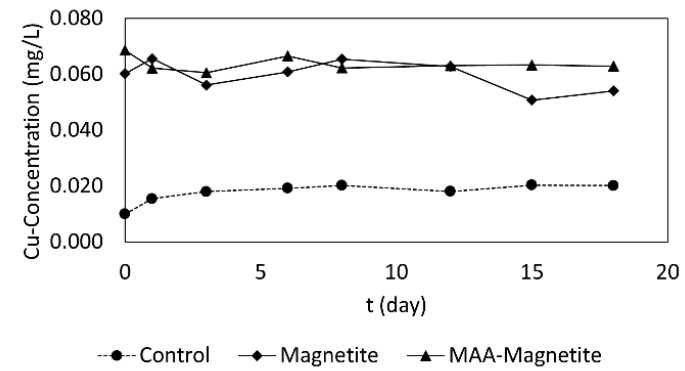

(b)

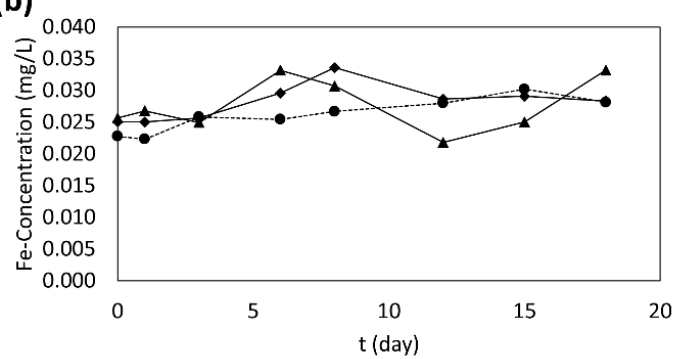

(d)

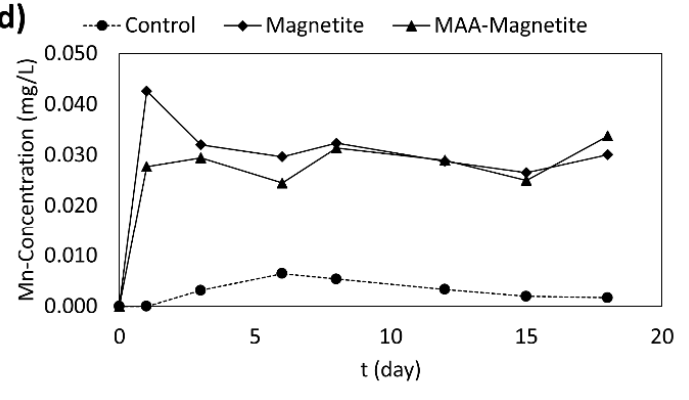

(f)

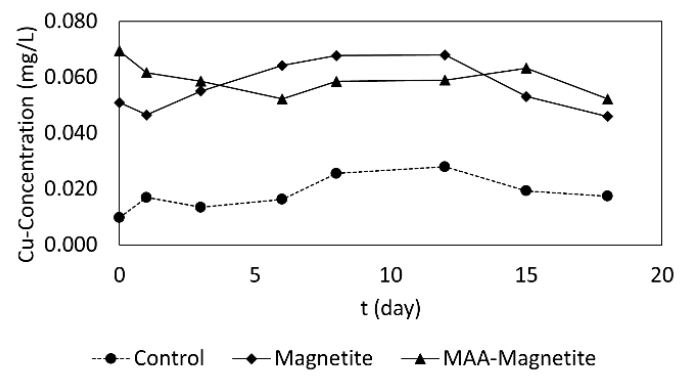

Figure 3. Residual concentrations of: $\mathrm{Fe}(\mathbf{a}, \mathbf{b}) ; \mathrm{Mn}(\mathbf{c}, \mathbf{d})$; and $\mathrm{Cu}(\mathbf{e}, \mathbf{f})$, while treating $\mathrm{CBZ}(\mathbf{a}, \mathbf{c}, \mathbf{e})$; and DTZ $(\mathbf{b}, \mathbf{d}, \mathbf{f})$ in control, magnetite and MAA-magnetite amended sand columns

Increased concentrations of dissolved iron are usually observed during and after groundwater remediation with nano zerovalent iron in field water samples [21]. In present study, it was not possible to trace back the source of Fe in effluent i.e., whether originated from NPs dissolution or Fe leached from sand particles. However, differences in effluent Fe concentrations across the columns were evident. Iron oxide nanoparticle causes removal of most organic and inorganic contaminants by reduction and/or sequestration and precipitation process [22,23]. Carboxyl groups on MAA-magnetite 
surface are likely to be involved in the adsorption of metal ions such as Mn [24]. Reduction of Fe as well as Mn concentration (except in control columns) could be due to the increase of DOC and presence of magnetites. Manganese with more negative redox potentials than iron may be removed by adsorption and precipitation on the nanoparticle surface [23,25]. More electropositive metal ions, such as $\mathrm{Cu}$, are reduced by iron nanoparticles and favorably adsorbed on the surface of magnetite [8]. Metal adsorption or mobilization depends on DOC concentration [26]. In real aquifer scenario, with increased depth in soil profile, the concentration of DOC gets lowered and free ion metals are increased the metal left in the solution is regarded as DOM-complexed [27]. $\mathrm{Mn}$ and $\mathrm{Cu}$ adsorption on magnetite result from electron transfers. Due to competition for adsorption sites, presence of DTZ or CBZ ensures increased concentration of DOC available for complexing with $\mathrm{Cu}$ and $\mathrm{Ni}$, and its subsequent leaching.

\subsection{Characterization of the Magnetite before and after Column Test}

The core level $\mathrm{Fe}(2 \mathrm{p})$ and $\mathrm{O}(1 \mathrm{~s})$ spectra in magnetite and MAA-magnetite before and after column test are shown in Figures 4 and 5, respectively. For magnetite nanoparticles, peaks of Fe(2p) spectra $(710.54 \mathrm{eV})$ were slightly shifted either to negative or positive binding energies following CBZ (710.42 eV) or DTZ (710.63 eV) adsorption. Similarly, peak shift for O(1s) spectra (529.68 eV) on CBZ $(529.66 \mathrm{eV})$ and DTZ $(529.93 \mathrm{eV})$ adsorption were negligible. When MAA-magnetite was added to column, peaks of $\mathrm{Fe}(2 \mathrm{p})$ spectra $(710.71 \mathrm{eV})$ were slightly shifted to positive binding energies (710.92 and $710.93 \mathrm{eV}$ ). Similar changes in $\mathrm{O}(1 \mathrm{~s})$ peaks were noted following CBZ or DTZ adsorption.

(a)

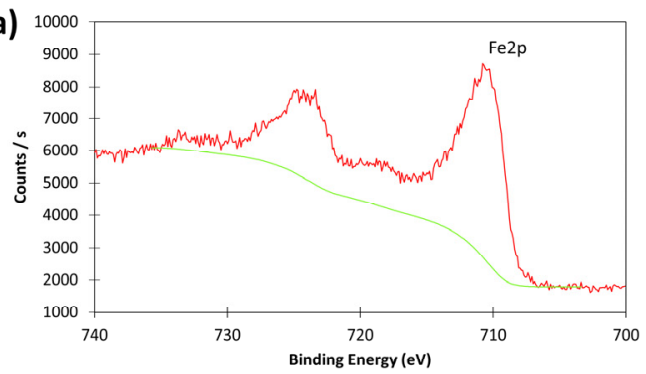

(c)

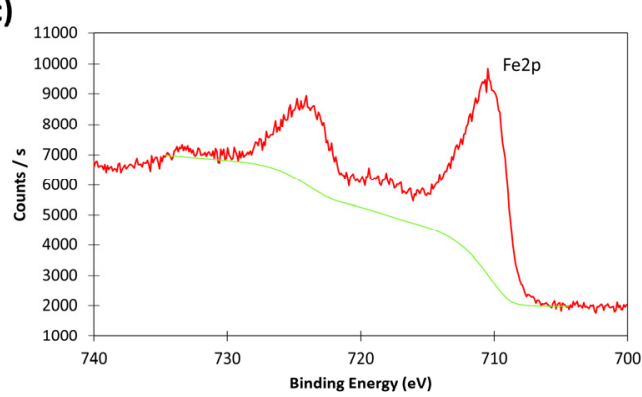

(e)

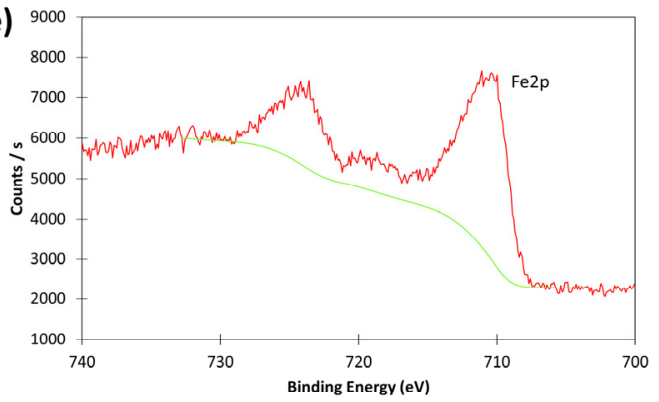

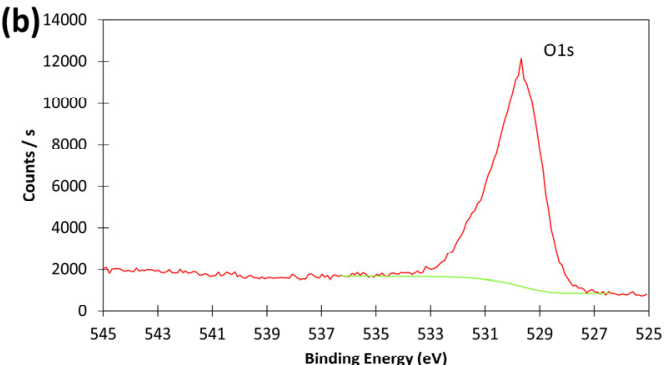

(d)
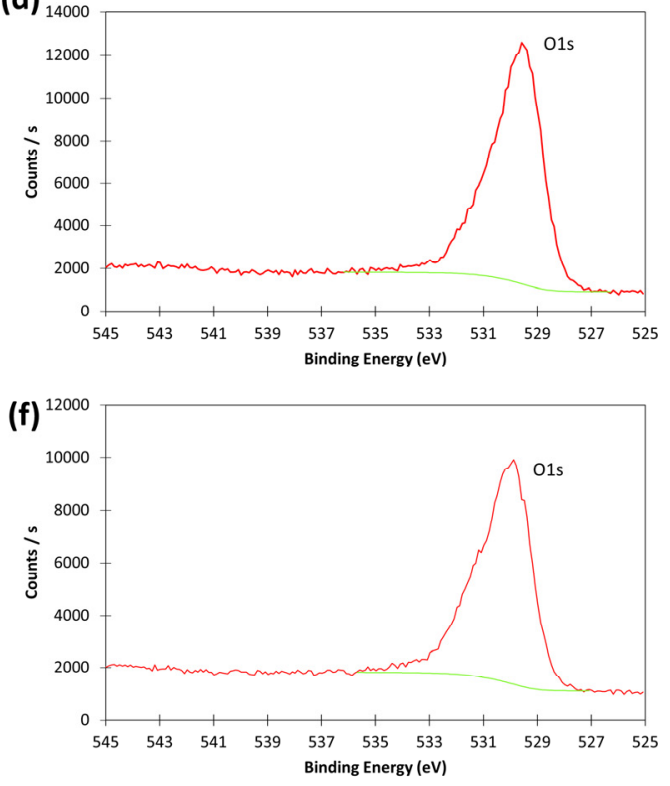

Figure 4. Core-level photoelectron spectra of $\mathrm{Fe}(2 \mathrm{p})$ for: magnetite (a); before and after (b) CBZ; or (c) DTZ adsorption in column test; and the corresponding $\mathrm{O}(1 \mathrm{~s})$ spectra $(\mathbf{d}-\mathbf{f})$. 

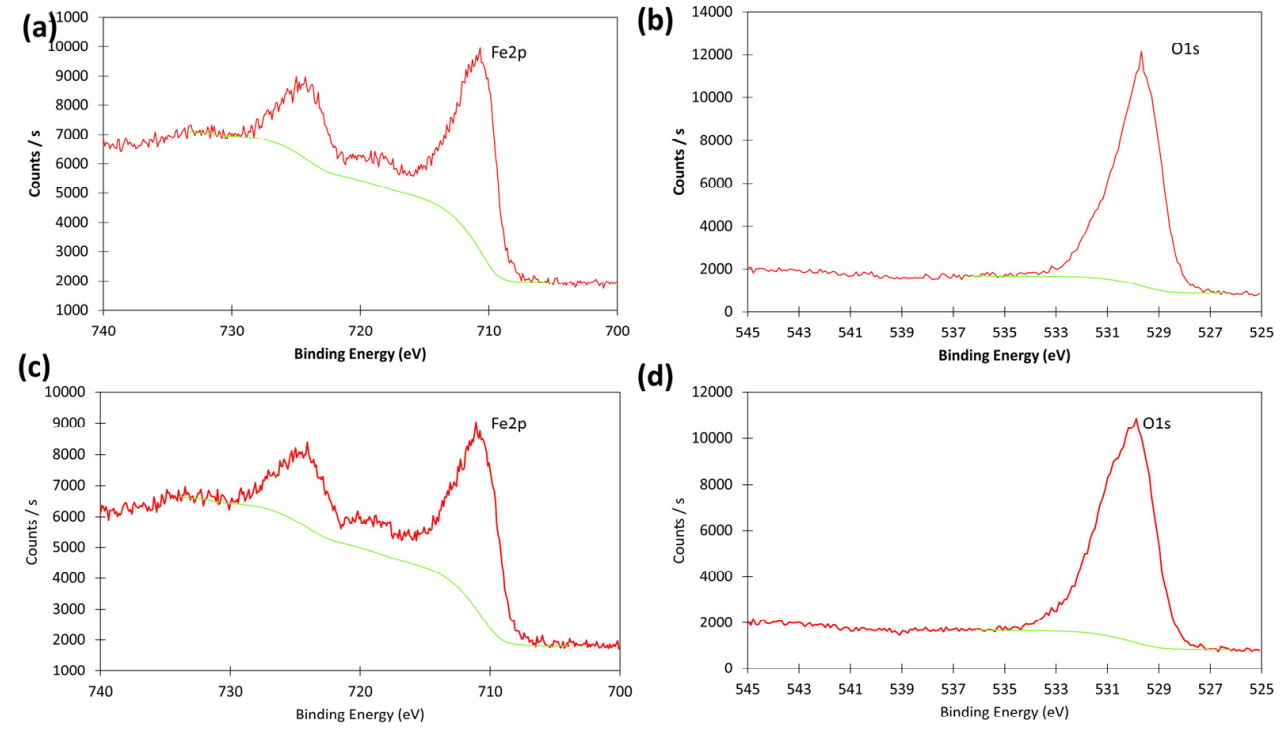

(d)
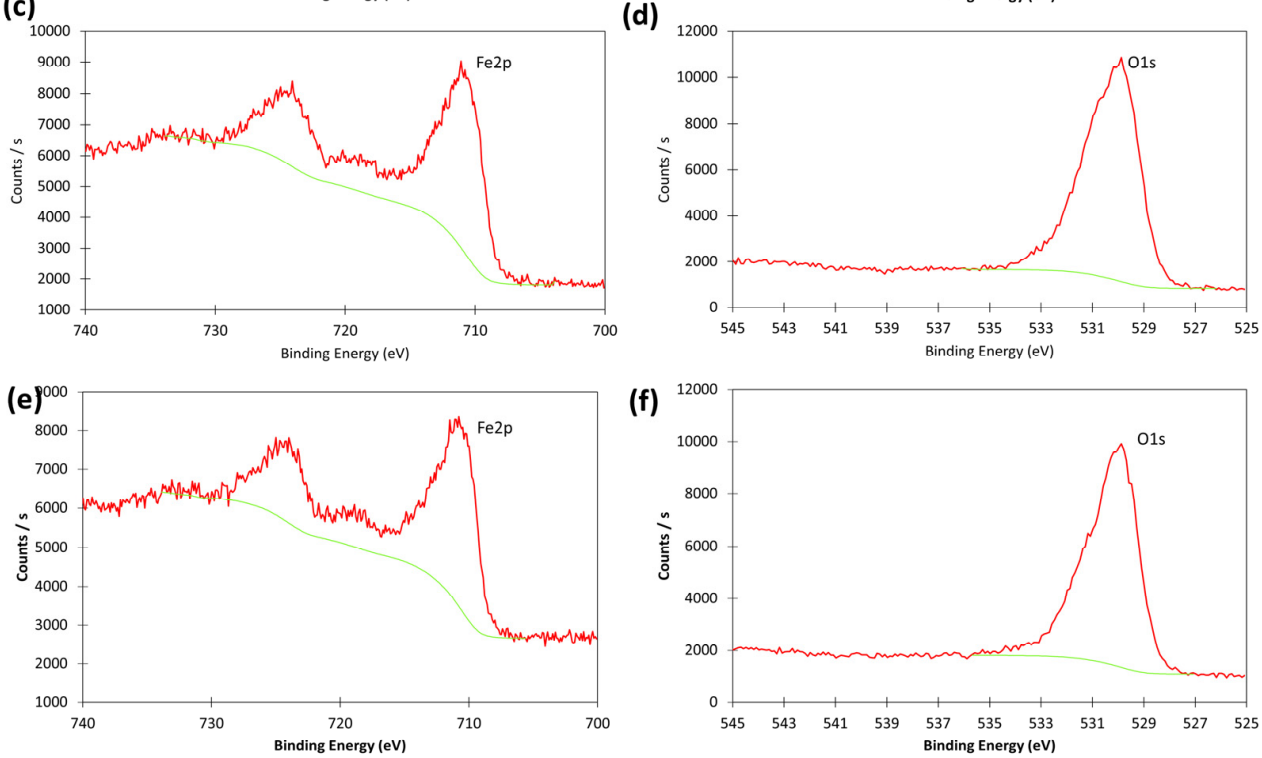

Figure 5. Core-level photoelectron spectra of Fe(2p) for: MAA-magnetite (a); before and after (b) CBZ; or (c) DTZ adsorption in column test; and the corresponding $\mathrm{O}(1 \mathrm{~s})$ spectra (d-f).

Use of XPS analysis to interpret adsorption mechanism of pharmaceutical compounds over $\mathrm{Fe}_{3} \mathrm{O}_{4}$ nanoparticle surface has not been reported earlier. However, slight peak shift for $\mathrm{Fe}(2 \mathrm{p})$ and $\mathrm{O}(1 \mathrm{~s})$ core level spectra with magnetite and MAA-magnetite has been observed following phenol adsorption in batch studies [11]. In other words, changes in binding energies are evident when organics are adsorbed to magnetite and MAA-magnetite. Similar spectral shift has been reported for C1s binding energy on alkanethiol adsorption on oxidized silver surface contaminated by hydrocarbons [28]. The O1s line for sorbed $\mathrm{H}_{2} \mathrm{O}$ monomer on the $\mathrm{Si}-\mathrm{H}$ surface is centered at $533 \mathrm{eV}$, consistent with those observed previously for physisorbed water layers [29]. The O1s line shifts slightly to lower binding energy upon exposure and a distinct shoulder develops at $531 \mathrm{eV}$ [30]. Many researches have suggested O1s peak $(529.6 \mathrm{eV})$ shifts for $0.1 \mathrm{eV}$ as a result of electrostatic interactions [31].

\section{Conclusions}

Feasibility of magnetite or MAA coated magnetite nanoparticle dosed sand adsorption column to treat CBZ and DTZ was evaluated. High level physisorption of CBZ or DTZ and lower extent of DOC leaching in MAA-magnetite dosed sand column implicates its suitability in MAR application. However, further studies are warranted to assess the long-term fate and ecotoxicity of the engineered nanoparticles before adoption in MAR system.

Acknowledgments: This work was supported by a grant from "The GAIA Project" funded by the Ministry of Environment, Korea (2014000550004).

Author Contributions: Soon Uk Yoon and Chang Gyun Kim conceived and designed the experiments; Soon Uk Yoon performed the experiments; Soon Uk Yoon and Biswanath Mahanty analyzed the data; Chang Gyun Kim contributed reagents/materials/analysis tools; Soon Uk Yoon and Biswanath Mahanty wrote the paper. 
Conflicts of Interest: The authors declare no conflict of interest.

\section{References}

1. Cunningham, V.L. Special Characteristics of Pharmaceuticals Related to Environmental Fate. In Pharmaceuticals in the Environment: Sources, Fate, Effects and Risks; Springer: New York, NY, USA, 2004; p. 19.

2. Lekkerkerker-Teunissen, K.; Chekol, E.T.; Maeng, S.K.; Ghebremichael, K.; Houtman, C.J.; Verliefde, A.R.D.; Verberk, J.Q.J.C.; Amy, G.L.; Van Dijk, J.C. Pharmaceutical removal during managed aquifer recharge with pretreatment by advanced oxidation. Water Sci. Technol. Water Supply 2012, 12, 755-767. [CrossRef]

3. Li, D.; Alidina, M.; Ouf, M.; Sharp, J.O.; Saikaly, P.; Drewes, J.E. Microbial community evolution during simulated managed aquifer recharge in response to different biodegradable dissolved organic carbon (BDOC) concentrations. Water Res. 2013, 47, 2421-2430. [CrossRef] [PubMed]

4. Kazner, C.; Wintgens, T.; Dillo, P.J. Water Reclamation Technologies for Safe. Managed Aquifer Recharge; IWA Publishing: London, UK, 2012.

5. Dillon, P. Future management of aquifer recharge. Hydrogeol. J. 2005, 13, 313-316. [CrossRef]

6. Quanrud, D.M.; Arnold, R.G.; Wilson, L.G.; Gordon, H.J.; Graham, D.W.; Amy, G.L. Fate of Organics During Column Studies of Soil Aquifer Treatment. J. Environ. Eng. 1996, 122, 314-321. [CrossRef]

7. Maeng, S.K.; Sharma, S.K.; Lekkerkerker-Teunissen, K.; Amy, G.L. Occurrence and fate of bulk organic matter and pharmaceutically active compounds in managed aquifer recharge: A review. Water Res. 2011, 45, 3015-3033. [CrossRef] [PubMed]

8. Xu, P.; Zeng, G.M.; Huang, D.L.; Feng, C.L.; Hu, S.; Zhao, M.H.; Lai, C.; Wei, Z.; Huang, C.; Xie, G.X.; et al. Use of iron oxide nanomaterials in wastewater treatment: A review. Sci. Total Environ. 2012, 424, 1-10. [CrossRef] [PubMed]

9. Yu, S.; Moog, G. Carboxyl group (- CO 2 H ) functionalized ferrimagnetic iron oxide nanoparticles for potential bio-applications. J. Mater. Chem. 2004, 14, 2781-2786. [CrossRef]

10. Yoon, S.U.; Mahanty, B.; Kim, C.-G.G. Preparation of superparamagnetic iron oxide nanoparticles and evaluation of their adsorption capacity toward carbamazepine and diatrizoate. Desalin. Water Treat. 2016, 57, 7789-7800. [CrossRef]

11. Yoon, S.U.; Mahanty, B.; Ha, H.M.; Kim, C.G. Phenol adsorption on surface-functionalized iron oxide nanoparticles: Modeling of the kinetics, isotherm, and mechanism. J. Nanopart. Res. 2016, 18. [CrossRef]

12. Clara, M.; Strenn, B.; Kreuzinger, N. Carbamazepine as a possible anthropogenic marker in the aquatic environment: Investigations on the behaviour of Carbamazepine in wastewater treatment and during groundwater infiltration. Water Res. 2004, 38, 947-954. [CrossRef] [PubMed]

13. Arye, G.; Dror, I.; Berkowitz, B. Fate and transport of carbamazepine in soil aquifer treatment (SAT) infiltration basin soils. Chemosphere 2011, 82, 244-252. [CrossRef] [PubMed]

14. Ghosh, S.; Badruddoza, A.Z.M.; Hidajat, K.; Uddin, M.S. Adsorptive removal of emerging contaminants from water using superparamagnetic $\mathrm{Fe} 3 \mathrm{O} 4$ nanoparticles bearing aminated $\beta$-cyclodextrin. J. Environ. Chem. Eng. 2013, 1, 122-130. [CrossRef]

15. Bui, T.X.; Choi, H. Adsorptive removal of selected pharmaceuticals by mesoporous silica SBA-15. J. Hazard. Mater. 2009, 168, 602-608. [CrossRef] [PubMed]

16. Chen, W.; Liu, Y.; Liu, C. Preparation and use of magnetic poly(glycidyl methacrylate) resin in drinking water treatment. J. Appl. Polym. Sci. 2013, 130, 106-112. [CrossRef]

17. Suriyanon, N.; Punyapalakul, P.; Ngamcharussrivichai, C. Mechanistic study of diclofenac and carbamazepine adsorption on functionalized silica-based porous materials. Chem. Eng. J. 2013, 214, 208-218. [CrossRef]

18. Berry, C.C.; Curtis, A.S.G. Functionalisation of magnetic nanoparticles for applications in biomedicine. J. Phys. D Appl. Phys. 2003, 36, R198-R206. [CrossRef]

19. Chefetz, B.; Mualem, T.; Ben-Ari, J. Sorption and mobility of pharmaceutical compounds in soil irrigated with reclaimed wastewater. Chemosphere 2008, 73, 1335-1343. [CrossRef] [PubMed]

20. Scheytt, T.; Mersmann, P.; Rejman-Rasinski, E.; These, A. Tracing pharmaceuticals in the unsaturated zone. J. Soils Sediments 2007, 7, 75-84. [CrossRef]

21. Elliott, D.W.; Zhang, W.X. Field assessment of nanoscale bimetallic particles for groundwater treatment. Environ. Sci. Technol. 2001, 35, 4922-4926. [CrossRef] [PubMed] 
22. Shi, Z.; Fan, D.; Johnson, R.L.; Tratnyek, P.G.; Nurmi, J.T.; Wu, Y.; Williams, K.H. Methods for characterizing the fate and effects of nano zerovalent iron during groundwater remediation. J. Contam. Hydrol. 2015, 181, 17-35. [CrossRef] [PubMed]

23. O'Carroll, D.; Sleep, B.; Krol, M.; Boparai, H.; Kocur, C. Nanoscale zero valent iron and bimetallic particles for contaminated site remediation. Adv. Water Resour. 2013, 51, 104-122. [CrossRef]

24. Grafe, M.; Eick, M.J.; Grossl, P.R.; Saunders, A.M. Adsorption of Arsenate and Arsenite on Ferrihydrite in the Presence and Absence of of Dissolved Organic Carbon. J. Environ. Qual. 2002, 31, 1115-1123. [CrossRef] [PubMed]

25. Morrison, S.J.; Metzler, D.R.; Dwyer, B.P. Removal of As, Mn, Mo, Se, U, V and Zn from groundwater by zero-valent iron in a passive treatment cell: Reaction progress modeling. J. Contam. Hydrol. 2002, 56, 99-116. [CrossRef]

26. Kalbitz, K.; Wennrich, R. Mobilization of heavy metals and arsenic in polluted wetland soils and its dependence on on dissolved organic matter. Sci. Total Environ. 1998, 209, 27-39. [CrossRef]

27. Weng, L.; Temminghoff, E.J.M.; Lofts, S.; Tipping, E.; Van Riemsdijk, W.H. Complexation with dissolved organic matter and solubility control of heavy metals in a sandy soil. Environ. Sci. Technol. 2002, 36, 4804-4810. [CrossRef] [PubMed]

28. Grunze, M.; Eisert, F.; Himmelhaus, M.; Buck, M.; Wöll, C.; Gauss, I. Adsorption of docosanethiol from solution on polycrystalline silver surfaces: An XPS and NEXAFS study. J. Electron. Spectros. Relat. Phenomena 1998, 92, 139-149.

29. Takagi, N.; Minami, N.; Furukawa, T.; Nishijima, M. The growth of ice clusters on the Si (100)(2Xl)-H(D) surface: Electron energy loss spectroscopy and thermal desorption studies. Surf. Sci. Lett. 1993, 297, L43-L47. [CrossRef]

30. Klyachko, D.; Rowntree, P.; Sanche, L. Oxidation of hydrogen-passivated silicon surfaces induced by dissociative electron attachment to physisorbed H 2 O. Surf. Sci. 1996, 346, L49-L54. [CrossRef]

31. Guilbert, S.; Guittet, M.J.; Barré, N.; Gautier-Soyer, M.; Trocellier, P.; Gosset, D.; Andriambololona, Z. Dissolution of UO2 in Boom clay water in oxidizing conditions: An XPS study. J. Nucl. Mater. 2000, 282, 75-82. [CrossRef]

(c) 2017 by the authors. Licensee MDPI, Basel, Switzerland. This article is an open access article distributed under the terms and conditions of the Creative Commons Attribution (CC BY) license (http:/ / creativecommons.org/licenses/by/4.0/). 